\title{
New Classification of Polydactyly of the Foot on the Basis of Syndactylism, Axis Deviation, and Metatarsal Extent of Extra Digit
}

\author{
Hyo Hyun Seok, Ji Ung Park, Sung Tack Kwon \\ Department of Plastic and Reconstructive Surgery, Seoul National University College of Medicine, Seoul, Korea
}

Background Polydactyly of the foot is one of the most frequent anomalies of the limbs. However, most classification systems are based solely on morphology and tend to be inaccurate and less relevant to surgical methods and results. The purpose of this study is to present our new classification of polydactyly of the foot, which can serve as a predictor of treatment and prognosis.

Methods To find a correlation between the various morphologic traits of polydactyly of the foot and the treatment plan and outcomes, we reviewed 532 cases of polydactyly of the foot in 431 patients treated in our hospital, expanding on our previous study that described polydactyly based on the importance of metatarsal bone status and varus deformity. The records of patients were evaluated and compared with previous studies at other centers.

Results Unsatisfactory results were seen in 36 cases, which included 5 cases of incomplete separation due to syndactylism, 23 cases of axis deviation, and 8 cases of remnants of extradigit metatarsal bones. The locus of the polydactyly, or the digit which was involved, did not seem to affect the final postoperative outcomes in our study. Three factors-syndactylism, axis deviation, and metatarsal extension-are the major factors related to treatment strategy and prognosis. Therefore, we developed a new classification system using three characters $(S, A, M)$ followed by three groups $(0,1,2)$, to describe the complexity of polydactyly of the foot, such as $\mathrm{S}_{1} \mathrm{~A}_{2} \mathrm{M}_{2}$.

Conclusions Our new classification could provide a communicable description to help determine the surgical plan and predict outcomes.

Keywords Polydactyly / Foot / Classification / Syndactyly / Axis
Correspondence: Sung Tack Kwon Department of Plastic and Reconstructive Surgery, Seoul National University College of Medicine, 101 Daehak-ro, Jongno-gu, Seoul 110-744, Korea

Tel: $+82-2-760-3759$

Fax: +82-2-745-5986

E-mail: stk59@snu.ac.kr
This article was presented at the 69th Congress of the Korean Society of Plastic and Reconstructive Surgeons on November 11-13, 2011 in Seoul, Korea.

No potential conflict of interest relevant to this article was reported.

\section{INTRODUCTION}

Polydactyly of the foot is one of the most frequent anomalies of the limbs, accounting for $45 \%$ of congenital foot abnormalities $[1,2]$. Polydactyly of the foot, like polydactyly of the hand, has various morphologic phenotypes. The surgical methods are diverse, and the prognosis varies greatly. Nevertheless, classification of polydactyly of the foot has received little attention relative to that of the hand, although some authors have attempted to classify polydactyly of the foot in past publications [1,3-10]. Their cases were usually classified by representative conventional systems used in hand polydactyly, such as the Wassel classifica- 
tion [11], Stelling and Turek's classification [12], and the Hirase classification [13]. These conventional classification systems have many limitations when applied to polydactyly of the foot. They are unclear, inaccurate, and have little relevance to surgical methods and outcomes. Therefore, a simple and clear classification system has been sought for polydactyly of the foot. Previously, we reported 129 polydactyly cases in 96 patients [1]. We focused on the metatarsal bone status of polydactyly and varus deformity after surgery. This report propelled us to formulate a more systematized classification method.

The surgical management of polydactyly is commonly performed for cosmetic and psychological reasons in Asian countries. Parental concerns about the external appearance of children in the Republic of Korea have contributed to the magnitude of our study and the development of a communicable classification of polydactyly, which we have named "SAM."

The purpose of this paper is to present our new classification of polydactyly of the foot. The surgical treatment in polydactyly of the foot is straightforward, but must be individualized according to its type, and anatomical details should be considered preoperatively to obtain more satisfactory results. We developed a classification system to describe, in a more effective way the different anatomical patterns of polydactyly of the foot and to evaluate the surgical methods, complications, and residual deformities, according to these patterns.

\section{METHODS}

The subjects of the study were consecutive patients in the past 16 years, from March 1996 to June 2012. We have reviewed 532 cases of polydactyly of the foot in 431 patients surgically treated by a single experienced surgeon at our hospital. The age at surgery ranged from 0.8 to 3 years, with a mean age of 1.7 years. The records of the patients including clinical data and radiographs of sufficient quality were available.

Table 1. Polydactyly in the foot according to Wassel's classification system, showing no definite relationship to commonly found unsatisfactory postoperative results

\begin{tabular}{|lrccc|}
\hline $\begin{array}{l}\text { Wassel's } \\
\text { classification }\end{array}$ & $\begin{array}{c}\text { Axis } \\
\text { deviation }\end{array}$ & $\begin{array}{c}\text { Incomplete } \\
\text { separation }\end{array}$ & $\begin{array}{c}\text { Remnant } \\
\text { metatarsal bone }\end{array}$ \\
\hline I & - & - & - & - \\
II & - & - & - & - \\
III & 1 & 1 & 1 & - \\
IV & 13 & 8 & 1 & 1 \\
V & 10 & 7 & - & 2 \\
VI & 7 & 4 & 1 & 2 \\
VII & 7 & 3 & 2 & 8 \\
Total & 38 & 23 & 5 & 2 \\
\hline
\end{tabular}

All of the subjects were categorized according to their varying anatomical patterns of polydactyly of the foot and were evaluated in terms of surgical methods, complications, and residual deformity. Photographs of each patient were reviewed to assess the level of syndactylism and degree of angulation. The radiographs of each patient were reviewed to assess metatarsal involvement.

The cases were initially grouped using classical classification systems such as the Wassel classification [11], Stelling and Turek's classification [12], and the Hirase classification [13]. Subsequently, the cases were grouped and analyzed according to our newly developed classification system, and we compared the results. This study was approved by the Institutional Review Board of the Seoul National University Hospital (H-1212-104453).

\section{RESULTS}

Our cases included 210 males and 221 females, and polydactyly of the foot was present on the right foot in 260 cases, the left foot in 272 cases, and bilateral feet in 101 cases. Consistent with past publications, the majority, involving 448 cases (84\%), were of the postaxial type, followed by the preaxial type with $47(8 \%)$ and central type with 37 (6\%) [14].

Analyses based on the grouping by previous classification systems are summarized in Tables 1-3. Wassel type IV (13 cases), Hirase type B-1 (196 cases), and Stelling and Turek type 1 (277 cases) were the most common type in each classification system. Unsatisfactory results requiring secondary surgery were

Table 2. Polydactyly in the foot according to Hirase's classification system, showing no definite relationship to commonly found unsatisfactory postoperative results

\begin{tabular}{|lrccc|}
\hline $\begin{array}{l}\text { Hirase's } \\
\text { classification }\end{array}$ & No. & $\begin{array}{c}\text { Axis } \\
\text { deviation }\end{array}$ & $\begin{array}{c}\text { Incomplete } \\
\text { separation }\end{array}$ & $\begin{array}{c}\text { Remnant } \\
\text { metatarsal bone }\end{array}$ \\
\hline Type A & 162 & 11 & - & 2 \\
Type B-1 & 196 & 8 & 3 & 3 \\
Type B-2 & 90 & 4 & 2 & 3 \\
Total & 458 & 23 & 5 & 8 \\
\hline
\end{tabular}

Table 3. Polydactyly in the foot according to Stelling and Turek's classification and no definite relationship to commonly found unsatisfactory postoperative results

\begin{tabular}{|lrccc|}
\hline $\begin{array}{l}\text { Stelling and } \\
\text { Turek's } \\
\text { classification }\end{array}$ & No. & $\begin{array}{c}\text { Axis de- } \\
\text { viation }\end{array}$ & $\begin{array}{c}\text { Incomplete } \\
\text { separation }\end{array}$ & $\begin{array}{c}\text { Remnant } \\
\text { metatarsal bone }\end{array}$ \\
\hline 1 & 277 & - & 3 & - \\
2 & 192 & 10 & 1 & 8 \\
3 & 66 & 13 & 1 & - \\
Total & 435 & 23 & 5 & 8 \\
\hline
\end{tabular}




\section{Fig. 1. Special considerations in applying SAM clinically}

$(A, B, C)$ Fifth toe polydactyly. This case was classified as $S_{0} A_{2} M_{2}$ by the SAM classification. Medial ray excision was performed. In this case, lateral ray excision would have been appropriate because we could have avoided unnecessary primary wedge ostectomy and reduced hospital admission hours. This case would be $S_{0} A_{0} M_{2}$ if the excised toe belonged to the lateral ray. (D, E) Postoperative deformities: web widening and angulation deformity. S, syndactylism; $A$, axis deviation; $M$, metatarsal extension.
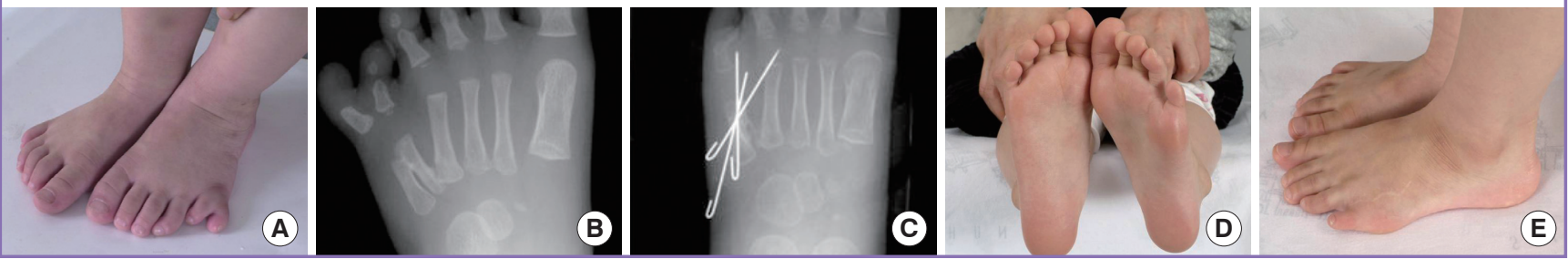

Fig. 2. A example of proper classification of SAM, preoperatively

(A) Preoperative photograph. (B) Satisfactory results two years postoperatively. In both feet, after lateral toe excision, reconstruction of the collateral ligaments was performed for alignment. No web widening was observed. $S$, syndactylism; $A$, axis deviation; $M$, metatarsal extension.
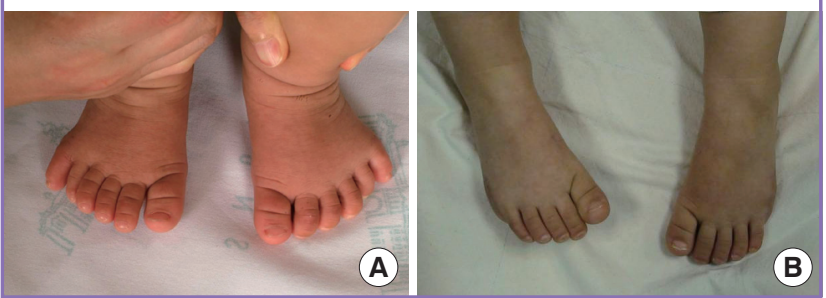

Table 4. Summary of new classification: SAM

\begin{tabular}{|lccc|}
\hline $\begin{array}{c}\text { SAM clas- } \\
\text { sification }\end{array}$ & $\begin{array}{c}\text { Syndactylism to } \\
\text { the adjacent toe }\end{array}$ & $\begin{array}{c}\text { A } \\
\text { Angulation/ } \\
\text { Deviation }\end{array}$ & $\begin{array}{c}\text { M } \\
\text { Metatarsal } \\
\text { extension }\end{array}$ \\
\hline 0 & No & $<15^{\circ}$ & No \\
1 & Incomplete, $<1 / 2$ & $15^{\circ} \leq<30^{\circ}$ & $\begin{array}{c}\text { Metatarsal head shared, } \\
\text { but shaft (-) }\end{array}$ \\
2 & $\begin{array}{l}1 / 2 \leq \leq \text { complete, } \\
\text { complex syndactyly }\end{array}$ & $\geq 30^{\circ}$ & Shaft (+) and more \\
\hline S, syndactylism; A, axis deviation; M, metatarsal extension. & \\
\hline
\end{tabular}

seen in 36 cases, which included five cases of web recurrence due to incomplete separation of syndactylism, 23 cases of angulation deformity due to axis deviation, and 8 cases of remnant metatarsal bones of the extra digit.

Web recurrence occurred in three cases of polydactyly with complete syndactylism and two cases of polydactyly with incomplete syndactylism, with no incidence in simple polydactyly. Twenty-three cases of angulation deformity exhibited preoperative axis deviation greater than $15^{\circ}$. Seven cases of residual bony deformities were associated with their duplicated metatarsal shaft. Residual bony deformity occurred in one patient with a broad-headed metatarsal bone. No complications occurred in the group with no metatarsal extension (Figs. 1, 2).

There was no definite correlation between these conventional

\section{Fig. 3. $\mathrm{S}_{1} \mathrm{~A}_{2} \mathrm{M}_{3}$ polydactyly}

(A) Relationship of the ideal axis line of the remnant toe to the existing preoperative axis (purple line, existing preoperative axis; green line, ideal axis line of remnant toe = expected postoperative axis). The sixth toe was excised for a more normal contour and satisfactory postoperative results in this case. (B) This radiologic findings represent $\mathrm{S}_{3}$ polydactyly. $\mathrm{S}$, syndactylism; $\mathrm{A}$, axis deviation; $\mathrm{M}$, metatarsal extension.
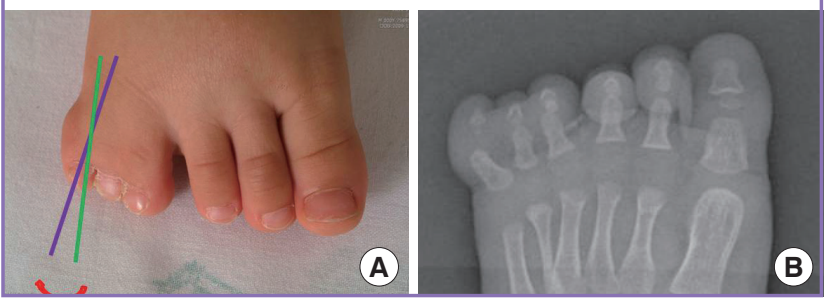

classifications and commonunsatisfactory postoperative results, such as axis deviation, incomplete separation, and residual metatarsal bony deformities.

\section{Suggested New Classification System: SAM}

( $S$, syndactylism; $A$, axis deviation; $M$, metatarsal extension)

We introduce a new classification system of polydactyly of the foot. Categorization is based on syndactylism, axis deviation, and metatarsal extension and is summarized in Table 4.

\section{Syndactylism}

Each $S$ group is defined as follows: 1) $S_{0}$ : Simple polydactyly, which does not have any syndactylism with the adjacent toe preserved after excision of the extra digit. 2) $S_{1}$ : Incomplete syndactylism of the adjacent toe preserved after excision of the extra digit, with webbing involving less than half of the total length of the involved digits. 3) $\mathrm{S}_{2}$ : Syndactylism with greater than half of the digit length or complete syndactylism, or complex syndactylism of the adjacent toe preserved after excision of the extra digit.

\section{Axis deviation}

Each A group is defined as follows: 1) $\mathrm{A}_{0}$ : Angulation, less than 


\section{Fig. 4. Extent of extra metatarsal digit}

M, metatarsal extension.

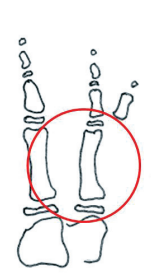

$M_{0}$

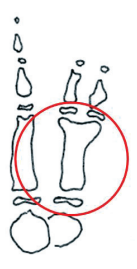

$M_{1}$
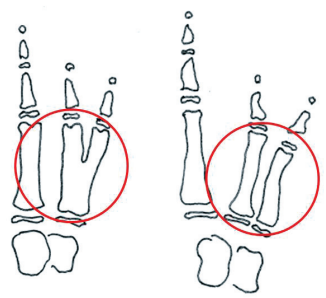

$\mathrm{M}_{2}$
Fig. 5. $M_{1}$ polydactyly and $M_{2}$ polydactyly

These radiologic findings demonstrate $\mathrm{M}_{1}$ polydactyly of the right foot and $\mathrm{M}_{2}$ polydactyly of the left foot. $\mathrm{M}_{1}$ metatarsal extension.

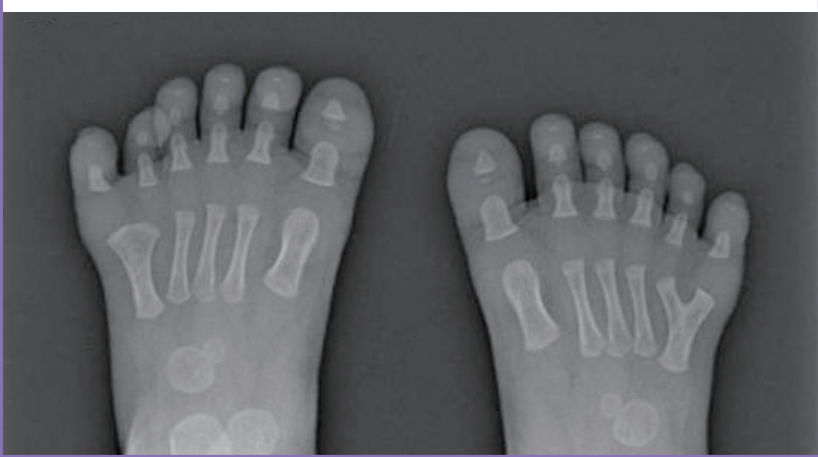

Table 5. Polydactyly in the foot according to the SAM classification

\section{Metatarsal extent of extra digit}

Each M group is described as follows and as illustrated in Fig. 4. 1) $M_{0}$ : No metatarsal involvement. 2) $M_{1}$ : Broad-headed metatarsal bone. No shaft duplication. 3) $\mathrm{M}_{2}$ : Y-shaped metatarsal bone or complete duplication of the metatarsal bone (Fig. 5).

The application of the SAM classification in our patient group is summarized in Table 5. According to our new classification, the $S_{0}$ type (58\%), $A_{1}$ type (45\%), and $\mathrm{M}_{1}(42 \%)$ types were most commonly found in each category. Combining the three categories, the most common anatomical pattern was the $S_{1} A_{0}$ $\mathrm{A}_{1} \mathrm{M}_{0}-\mathrm{M}_{1}$ type.

\section{DISCUSSION}

Many attempts to classify polydactyly of the foot have been described in past publications [1,3-10]. Numerous authors, feeling the need for an organized overview, have attempted to devise a classification system for polydactyly of the foot. The most important studies on polydactyly of the foot are by Venn-Watson [4], who reported the results 3.2 years after treatment on a series of 65 patients and introduced an important morphological classification on the basis of the anatomic configuration of the metatarsal and the duplicated bony parts. Phelps and Grogan [5] were the first to report long-term results (mean 15 years) in a group of 61 patients, and Masada et al. [6] and Watanabe et al. [7] reported long-term results on 110 and 265 patients, respectively, treated in Japan [8]. However, despite many suggestions otherwise, these conventional classifications are based on morphology only and a classification taking into consideration the important aspects of polydactyly of the foot that can guide surgical planning and predict postoperative outcomes was yet to be introduced.

The surgical treatment of polydactyly could be thought of as

\begin{tabular}{|lcccccc|}
\hline Grade & $\mathrm{S}$ & $\begin{array}{c}\text { Incomplete } \\
\text { separation }\end{array}$ & $\mathrm{A}$ & $\begin{array}{c}\text { Axis } \\
\text { deviation }\end{array}$ & $\mathrm{M}$ & $\begin{array}{c}\text { Remnant } \\
\text { metatarsal bone }\end{array}$ \\
\hline 0 & 309 & - & 157 & - & 212 & - \\
1 & 163 & 2 & 238 & 8 & 226 & 1 \\
2 & 60 & 3 & 137 & 15 & 94 & 7 \\
Total & 532 & 5 & 532 & 23 & 532 & 8 \\
\hline S, syndactylism; A, axis deviation; M, metatarsal extension. \\
\hline
\end{tabular}

a simple practice of excising the extra digit, but it requires creativity and flexibility in the application of surgical techniques in order to restore an aesthetically pleasing, functional, and stable foot. To achieve satisfactory surgical results, surgical plans should be individualized. Therefore, preoperative assessment with an appropriate classification system is necessary [9].

During the analysis of our cases, we discovered that cases of revision operation for secondary deformities and unsatisfactory results usually resulted from axis deviation, incomplete separation of syndactylism, and remaining lesions of the extra digit, mainly occurring at the proximal portion of the involved metatarsal bone. Contrary to our expectation, the actual locus of polydactyly did not seem to affect final postoperative outcomes or patient satisfaction in polydactyly of the foot. Our aim was to build a classification system to predict these unsatisfactory results and further prevent these problems.

The excision of various types of extra digit is certainly the main procedure in surgery for polydactyly. However, in some cases, skin grafts and wedge ostectomies must be performed to correct axis deviation and prevent residual deformities of the digit to be preserved. These factors can determine the surgical time, hospitalization length, and surgical outcomes. The need for such procedures should be reflected in a proper classification system.

Based on this study, we introduce a new classification system, named "SAM." The basic principle of our proposed system is 
to classify polydactyly of the foot according to three categories. Each category is also subdivided into three groups. In this classification system, theoretically, 27 permutations $(3 \times 3 \times 3)$, or classes, are possible by combining the three categories, each with three groups.

Each category has its own meaning. The category of syndactylism $(S)$ reflects the requirement for skin graft during surgery. Syndactylism of the adjacent toe to be preserved determines the $S$ category. Through the syndactylism grouping $\left(S_{0}\right.$ to $\left.S_{2}\right)$, we expect to predict the surgical time and the amount of effort required from the surgeon during the skin graft. The $S_{0}$ group should require only simple division without skin grafting. $S_{1}$ to $\mathrm{S}_{2}$ requires skin grafting after division. Understanding the extent of syndactylism combined with polydactyly of the foot is important to prevent web recurrence and secondary surgery.

Axis deviation of the toe to be preserved (A) reflects the need for wedge ostectomy during surgery, and incomplete correction was the most common cause of secondary surgery in our cases. Through axis deviation grouping $\left(\mathrm{A}_{0}\right.$ to $\left.\mathrm{A}_{2}\right)$, we can preoperatively predict the need for wedge ostectomy, which, in turn, affects operation time. If angulation greater than $15^{\circ}\left(\mathrm{A}_{1}\right.$ to $\left.\mathrm{A}_{2}\right)$ is measured, we carefully perform wedge ostectomy to prevent further angulation deformity. To correct for axis deviation, wedge ostectomy and restoration of the collateral ligament of the extra digit was carefully performed.

The category of metatarsal extension (M) is an important component in the description of morphology and can help determine the surgical approach to treating the duplicated metatarsal bone. The metatarsal bone of the foot plays a significant role in sustaining the transverse arch of the foot, which functions as a support. Therefore, we must understand the extent of metatarsal duplication of the polydactyly to be treated $[2,15]$. In $M_{1}$ to $\mathrm{M}_{2}$ cases, we cannot exclude the possibility of postoperative residual bone deformity or angulation deformity.

In the clinical application of our classification system, we found some morphologically different groups with the same clinical implications and unified these groups into a single group. For example, complex syndactyly is a very rare condition, and instead of creating a separate group, we included this type with the clinically similar S2 group in which there is syndactylism of greater than half of the digit length. Division of cases with no angulation and cases with less than $15^{\circ}$ angulation into separate groups also turned out to be meaningless. In neither group did we perform primary wedge ostectomy during the initial operation, and the postoperative results were similar. In the $\mathrm{M}_{2}$ groups, which included morphologically different Y-shaped metatarsal bones and complete duplication, we were able to produce similar results by extending our incision on the dorsal side of the foot to remove the duplicated metatarsal bone. In this way, we were able to use SAM to classify cases into 27 possible groups $(3 \times 3 \times 3)$ clinically.

The SAM system could be compared to the conventional classification systems in several ways, as we mentioned above [1]. This new system is based on simultaneous radiological and morphological criteria. Additionally, we can customize surgical methods and preoperatively predict outcomes such as residual deformities.

The ideal classification of polydactyly of the foot must predict the various possible outcomes and help determine the treatment plan. The nomenclature of the system has to be easily understandable to paramedics as well as clinicians. We suggest a new classification system to provide a communicable description of the surgical plan and assess the predictability of outcomes as well as the morphological presentation, on which previous classification systems were based. Through our new SAM classification system, a clear and thorough treatment plan can be achieved interactively among different specialists including nurses, physical therapists, and plastic hand surgeons preparing for surgical treatment.

Our study also has some limitations. We did not assess the meaning of SAM statistically, and its advantages over other available classification methods still need to be verified. Further studies will be needed to demonstrate the role of SAM as a new powerful predictor of operation time and duration of hospital stay.

Our study is the largest-scale investigation of polydactyly of the foot and introduces the SAM classification as a new classification system for this condition. By applying the SAM classification, we can provide a better understanding and greater predictability of treatment outcomes, effectively perform individualized surgical treatment, and achieve more successful outcomes.

\section{REFERENCES}

1. Son WG, Kwon ST, Lee SW. Simple classification of foot polydactyly based on the status of metatarsal bone and varus deformity. J Korean Soc Plast Reconstr Surg 2004;31:501-5.

2. Miura T, Nakamura R, Imamura T. Polydactyly of the hands and feet. J Hand Surg Am 1987;12:474-6.

3. Kim HJ, Han SK, Lee BI, et al. Clinical study on polydactyly of the foot. J Korean Soc Plast Reconstr Surg 1997;24:31725.

4. Venn-Watson EA. Problems in polydactyly of the foot. Orthop Clin North Am 1976;7:909-27.

5. Phelps DA, Grogan DP. Polydactyly of the foot. J Pediatr Orthop 1985;5:446-51. 
6. Masada K, Tsuyuguchi Y, Kawabata H, et al. Treatment of preaxial polydactyly of the foot. Plast Reconstr Surg 1987; 79:251-8.

7. Watanabe H, Fujita S, Oka I. Polydactyly of the foot: an analysis of 265 cases and a morphological classification. Plast Reconstr Surg 1992;89:856-77.

8. Turra S, Gigante C, Bisinella G. Polydactyly of the foot. J Pediatr Orthop B 2007; 16:216-20.

9. Morley SE, Smith PJ. Polydactyly of the feet in children: suggestions for surgical management. Br J Plast Surg 2001; 54:34-8.

10. Blauth W, Olason AT. Classification of polydactyly of the hands and feet. Arch Orthop Trauma Surg 1988;107:334-44.

11. Wassel HD. The results of surgery for polydactyly of the thumb. A review. Clin Orthop Relat Res 1969;64:175-93.

12. Stelling F. The upper extremity. In: Fergusion AB, editor. Orthopedic surgery in infancy and childhood. Baltimore: Lippincott Williams \& Wilkins; 1963. p.304-9.

13. Konno M, Hirase Y. A clinical review of polydactyly in the foot and postoperative results of lateral ray polydactyly. J JPN Soc Plast Reconstr Surg 1997;17:211-25.

14. Coppolelli BG, Ready JE, Awbrey BJ, et al. Polydactyly of the foot in adults: literature review and unusual case presentation with diagnostic and treatment recommendations. J Foot Surg 1991;30:12-8.

15. Uda H, Sugawara Y, Niu A, et al. Treatment of lateral ray polydactyly of the foot: focusing on the selection of the toe to be excised. Plast Reconstr Surg 2002;109:1581-91. 